\section{Credit for Authorship}

SIR,-Your correspondent (Nature, 229, 436 ; 1971) on multiple authorship seems to wish to perpetuate the axiom "publish or perish" by his suggestion that each author be allocated a fractional amount of credit for a paper of which he is co-author. Whilst I recognize that this has become part of the "rat race", I abhor someone's trying to promote it. It is beyond my comprehension how one would arrive at the contribution of a particular author to a paper-for example, $10 \%$ practical contribution, $5 \%$ theoretical contribution and $55 \%$ "big name" contribution.

Perhaps, following on the lines of Schmid's letter, we should award a star rating to articles in a specific publication ("- and the five star paper of the month is") and conduct surveys on the lines of the one by Panton and Reuben ${ }^{1}$ to award a star rating to each scientific journal enabling authors to boast and ask their friends "How many stars do you have this year?". Or possibly one should take the Comprehensive Rating of Academic Proficiency formula proposed by Ramaley et al. ${ }^{2}$ if one is concerned with promotion and "success". The point here, of course, is that one doesn't start with the author, one starts with the quality of the scientific paper.

Surely the publication of a scientist's work is for the advancement of science and the sharing of one's knowledge and findings with the scientists of the world-or am I being too naive?

Yours faithfully, FRANK SNAPE

Department of Chemistry,

Dalhousie University,

Halifax, Nova Scotia

${ }^{1}$ Panton, D., and Reuben, B. G., Chem. in Britain, 7, 18 (1971).

${ }^{2}$ Ramaley, L., Coston, G., and Butcher, J., AAUP Bulletin, 55, 279 (1969).

\section{Expensive Meat}

SIR,-The non-biologist (Nature, 229, 435 ; 1971) suggested that tissue culture techniques be considered as a future supply of "meat". We have suggested that it may be possible to provide blood and blood products by the growth of human haematopoietic cells ${ }^{1}$ and considered the suggestion as quite "wild". The growth of cells for meat is several logs more remote even though the scientific capability is available. The limitations are (1) the division rate of cells acceptable for food ; (2) the cost of the culture media ; (3) expansion of the kind of "cell plants" that we at present use for growing large amounts of human cells ${ }^{2}$; and (4) avoidance of the spread of dangerous infections and abnormal genetic material and the like.

Normal human cells have a maximum division rate of approximately 19 to 20 hours and would, therefore, be unsuitable from a practical standpoint but one could feast on one's own lymphocytes if limited to hors d'oeuvres. We could grow about $1 \mathrm{~kg}$ of human lymphocytes per day in our 1,200 1 . culture unit. The cost per $\mathrm{kg}$ of this "meat" with present techniques would be as little as $\$ 2,500$ for the culture media.

The maximal division rate of mouse cells is about $9.5 \mathrm{~h}$ and would still pose a severe limitation on production even if a growth rate of $2 \mathrm{~g}$ of cells per $\mathrm{kg}$ of media could be sustained-and mouse meat may not be tasty.

We have fed residual cultured human cells to tropical fish for several years and can testify that the diet was apparently nutritious, supported rapid reproduction, and was not associated with the development of tumours.

Even the ethical problem will not be solved once we learn to grow animals and humans from single cells.

\section{Yours faithfully, \\ George E. Moore}

Roswell Park Memorial Institute,

666 Elm Street,

Buffalo,

New York 14203

${ }^{1}$ Moore, G. E., and Glick, J. L., Surgical Clinics of North America, 47, 1315 (1967).

${ }^{2}$ Moore, G. E., and Vosseller, G. V., in Methods in Enzymology (edit. by Jakoby, W. B.) (in the press).

\section{Numerical Etymology}

SiR,-The suggestion of R. M. Buroughs (Nature, 229, 142; 1971) for the consistent use of the sequence "million, billion, trillion, . . ." for the numbers $10^{\text {sn }}$, agreeing with standard usage in most of the world, and of another sequence "milliard, billiard, trilliard, . . ." for the numbers $10^{6\left(n+\frac{1}{2}\right)}$, formed analogously from the once universal "milliard", is an eminently sensible and natural one. It is not a new suggestion, however; the consistent use of both sequences was, I believe, first proposed by L. Gustave Du Pasquier (Proc. Intern. Math. Congr., 2, 975, University of Toronto Press, 1928).

The difficulty with N. W. Pirie's proposal of "gillion" and "tillion" (Nature, 229, 283 ; 1971) is-where do we go after "giant" and "monster" (Giga<

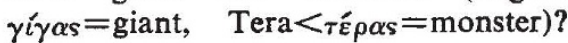

"King-size", perhaps? Unfortunately, $\beta \alpha \sigma \iota \lambda \varepsilon v$ s would give "billion" againnow $10^{15}$. I do not understand Pirie's criticism of "milliard" as a "vague word". I have never seen "milliard" defined or used to mean anything except $10^{9}$.

Returning to the $\mathrm{Du}$ PasquierBuroughs suggestion, a minor criticism is that, like the SI prefixes, it perpetuates the sextal (and ternary) system for counting indices, while the rest of our number system is decimal. In mathematical work where large integers, for example large prime numbers, have to be written out at length, and also in tables of more than 10 decimal places, it is not unusual for the digits to be arranged in blocks of five, not of six or three. Could some thought not be given to number names (and SI prefixes) based on powers of $10^{10}$ ? Individual names are already available in English for all the powers of 10 with single digit exponents, except for $10^{8}$; we already have "ten", "hundred", "thousand", "million", and "milliard", and the best dictionaries still list the borrowings "myriad" $\left(10^{4}\right)$, "lac" or "lakh" $\left(10^{5}\right)$, and "crore" $\left(10^{7}\right)$. All we need do is invent a name for $10^{3}$ and some systematic terminology for $10^{10}, 10^{20}, \ldots, 10^{90}$. For $10^{100}$, we have, of course, Kasner's "googol".

Yours faithfully,

THOMAS WRAY

Department of Energy,

Mines and Resources,

Ottawa 4,

Ontario

\section{British Diary}

\section{Monday, March 15}

Low Cost Digital Voltmeters (2.30 p.m. discussion) Institution of Electrical Engineers, at Savoy Place, London WC2.

Mitochondrial Structure and Function (5 p.m.) Professor Lars Ernster, University of London, in the Chemistry Auditorium, University College London, Gower Street, London WC1. (Further lectures on March 17 and 19.)

Physicochemical Aspects of Herbicide Selectivity (1.45 p.m. symposium) Society of Chemical Industry, Pesticides Group, at 14 Belgrave Square, London SW1.

The $300 \mathrm{GeV}$ Accelerator : For and Against (8 p.m. debate) British Society for Social Responsibility in Science, at the Institute of Contemporary Arts, Nash House, The Mall, London SW1. 